\title{
PROFILING AS A LOGICAL FORM OF REASONING IN ORDER TO SOLVE CONTROVERSIAL CIRCUMSTANCES ON THE CRIME SCENE
}

\author{
Pavel Palcu PhD \\ „Vasile Goldis” Western University of Arad \\ Anca Florina Morostes PhD \\ „Vasile Goldis” Western University of Arad \\ e-mail: ancamoro@yahoo.com
}

(Received November 2015; Accepted January 2016)

\begin{abstract}
While conducting research on the scene or during the entire phase of criminal prosecution, especially for the identification of the authors or settlement of the controversial circumstances, criminal profiling by a forensic psychologist will reduce the circle of suspects, as well as provide assistance in determining possible connections with other crimes and offer to judicial organs sustainable strategies for the solution of the case. In addition to identifying and processing the material traces found on the scene, concern falling strictly within forensics, in the future, efforts against criminality of the third millennium will be oriented towards the interpretation of human behaviour with criminogenic finality.
\end{abstract}

Key words: offender, profile, controversial circumstances, murder, on the scene, crime scene.

\section{Preliminary considerations}

If the crime scene provides conventional traces that can help outline probation and identification of authors, new concepts including: crime scene, scena del crimen or, in another meaning, profiler crime constitutes a real challenge towards the acceptance of a dynamic reality in progress, of the behavioural sequences, forcing the psychological component of the man of law (prosecutor, investigating judge, criminal prosecution body etc.) to interpret the reasons, intentions, reasoning, habits, logic, meaning, organization of criminogenic behaviours, in order to outline the psychological profile, the "behavioural mark" capable of drafting a gallery of potential portraits of the personalities included in the circle of suspects [1].

The methods of elaborating the criminal profiling have been accepted as scientific methods of criminal investigations in many American and Western European states, however, they do not have a probative value in the acceptance of criminal procedures [2].

Although it is used in Romania, profiling investigation has not been adopted strictly in these terms and, from a legal point of view, it is not among the means of evidence, according to the provisions of article $64 \mathrm{C}$ of Criminal Procedure. In this 
Profiling as a logical form of reasoning in order to solve controversial circumstances on the crime scene

respect, profiling is in the same situation as the sincerity test performed with polygraph type techniques, both in terms of applicability in the context of criminal investigation, and in terms of its admissibility as means of evidence.

For particularly serious cases, in several states, there have been established and developed special departments dealing with both the research and the creation of special criminal profiling methods, as well as with preparing specialized staff capable of leading complex investigations of the profiling type.

Thus, in 1950, in the USA, FBI created a major centre for profiling research and development, called Investigative Support Unit. The National Centre for the Analysis of Violent Crime in the US, which is in the composition of Critical Incident Response Group, formed a wide database, which contains information obtained by interviewing convicted criminals, information required to develop profiling.

In Europe, INTERPOL founded in 1993, a crime analysis unit called the Analytical Criminal Intelligence Unit (ACIU) through delinquency. ACIU assesses the size and nature of various criminal activities, including that of organized criminal groups, or serial killers, introducing structures, methods and techniques aimed at conducting a comprehensive analysis of the criminal phenomenon [3].

In specialized literature, the term "criminal profiling" [4] is used in a broad meaning: behavioural, statistical and geographical profile, the crime scene profile, the psychological profile of the participants to the criminal action etc. So far, there is no universally accepted definition of the term criminal profiling.

The investigating professional - the expert psychologist - is called in virtue of the issues referred to:

- in order to reproduce, through his own imagination, the circumstances and actions taken by the offender providing "the crime film in its dynamics" to the prosecuting authorities;

- in order to imagine the offender's profile, providing "his psycho-behavioural mark" to the prosecuting authorities;

- in order to anticipate "the next expected behaviour" counteracting future "acts" of the author by intuition of the optimal verses with reasonable degree of credibility in his identification [5].

All these form the subject of judicial psychology from the perspective of the impact of its interdisciplinarity with classical forensics, on the coordinates of a daring idea, the "forensic psychology". Therefore, the criminal act, as the dynamic expression of the criminogenic behaviours, suffers the impact of its interpretation in psycho-exploratory terms.

The profiler as a specialist in criminal profiling is described as a person who provides investigators some information customized to a particular type of individual who could commit a definite crime [6]. 
Palcu P., Morostes A.F., (2016)

Profiling as a logical form of reasoning in order to solve controversial circumstances on the crime scene

Profiling is, as some authors define it, a technique for determining the personality and behavioural characteristics of an individual, taking into account his criminal past, the various types of personalities of offenders who commit similar acts [7].

The elaboration of the profile appears to be a viable and important investigation instrument, which criminal prosecution authorities may use, especially in their confrontation with difficult cases. As statistics have shown, the cases that had the greatest benefit from using profiler expertise are the offenders who had mental, emotional or personality dysfunction [8].

The specialized literature [9], for example for homicide, revealed a grid of requirements that the scientific investigation of this sort of crime must answer:

1. What happened at the crime scene and which were the reasons of the murder?

$>$ legal meaning - the legal classification of the offense (rape, homicide, suicide, etc.);

$>$ psychological meaning (sexual satisfaction, suppression of life, property acquisition, vengeance, premeditated robbery, material interest, etc.)

2. Was the homicide committed at the place where the body was found?

$>$ forensic meaning (interpretation of impression evidence and dynamic traces);

3. Who was killed?

Legal meaning

Forensic meaning (the victim's identity)

4. When was the murder committed?

forensic meaning (checking the possible alibi)

forensic meaning (cadaver changes etc.)

5. How was murder committed?

$>$ legal meaning

$>$ psychological meaning (in terms of subjective aspect: intent, fault, self-defence etc.)

6. Did the murderer take steps in order to conceal the murder and which were they?

$>$ psychological meaning (the psychological profile of the author, criminal experience, duplicity, intelligence, simulation etc.)

7. Was the murder committed by one or by several persons?

$>$ legal meaning (author, accomplice, complicity etc.)

medical-legal meaning (number and kinds of injuries, the causality lesion weapon of defence or attack, the victim's strength, dynamics and disposition of injuries etc.)

8. Which are the ways the criminals access the crime scene, how did they leave the crime scene, how long did they stay there and what actions did they commit?

$>$ forensic meaning (dynamic and impression evidence interpretations)

$>$ psychological meaning (safety, precipitation, behaviour logic in conducting the crime scene) 
Profiling as a logical form of reasoning in order to solve controversial circumstances on the crime scene

9. Who is the offender?

$>$ legal meaning (determining liability and penalty)

$>$ forensic meaning (identification of the author)

10. What are the positive experiences and the limitations of the scientific investigation resulted from solving the case?

$>$ legal meaning

$>$ forensic meaning

$>$ psychological meaning (interpretation of the operating way; ex.: is it the case of a serial killer?)

The result of criminal profiling does not mean obtaining his name or his portrait, it rather means a psychological label which applies to the offender and gives a description of his personality, referring to age, gender, ethnicity, physical features type of disfigurement, weight, height, occupation, professional training, marital status, the type of house he could be living in, the type of car he could be driving, behavioural disorders, any speech defects or difficulties in his relationships with others [10].

The profiling assessment methods are used in two distinct stages of the criminal process [11].

1. Prosecution phase. In this phase, the purpose of profiling is to: reduce the circle of suspects; provide assistance in determining links that may exist with other crimes; provide investigative bodies with viable strategies of investigation.

2. The trial phase. The court may be helped to understand and interpret better the causes that led to criminal behaviour.

\section{Scientific methods of criminal profiling [12]}

In developing the offender's profile, the forensic psychologist typically takes into account the crime scene analysis, investigative psychology and behavioural evidence analysis

\subsection{The FBI Method: Crime scene analysis}

The FBI strategy consists of an assessment of six steps, which, if combined, shape the offender's profile:

1. Profiling inputs. This first step is extremely important as it is the basis of the other steps and of the entire process of elaborating the criminal profile. Any incomplete or badly documented information at this stage causes an erroneous approach of the subsequent investigation. Thus, the on-site investigation, with all its tactical and methodological elements, that are specific to each type of crime, followed by the assessment of their results, represents the basis of this stage. 


\section{JOURNAL OF LEGAL STUDIES}

"Vasile Goldiș" Western University of Arad

Palcu P., Morostes A.F., (2016)

Profiling as a logical form of reasoning in order to solve controversial circumstances on the crime scene

2. Decision Process Models. All information gathered in the previous step is assigned to a logical pattern so that, at this stage, it may be determined whether the crime in this case is part of a series of crimes committed by the same offender.

3. Crime Assessment. All these elements established in the previous step are used to determine what happened, in what order, as well as the role each participant had in the criminal event. It is actually a reconstruction of the sequence of events and behaviour of both the victim and the aggressor.

4. The criminal profile. Data is collected about the offender's background, education and culture, physical and behavioural characteristics, trying to establish the most appropriate conduct of identification, arrest and interrogation of the offender.

5. The Investigation. Once the criminal profile has been established, it is made available to the investigating authorities in order to be included in the case investigation strategy, but it is not defined, it can be subject to change if the investigation does not lead to the identification of any aspect or if new elements are discovered during the research.

7. The Apprehension. At the end the suspect's characteristics are compared to the profile made before the identification as such, but often this comparison or verification cannot be performed because the offender is not identified.

\subsection{The Canter Method: Investigative Psychology - IP [13]}

It is a method similar to the one used by the FBI, based on statistical data, except for the fact that the psychological investigation method (IP) created a database they constantly update with new data from criminal population research.

Any convicted individual is studied and assigned an offender group defined according to various characteristics, psychological profile, operating mode, and in case the criminals are unknown, the crime data are compared with those of the reference groups that already exist in the records. A list is made and compared with the existing data about the unknown aggressor and the greatest similarities are determined.

The method is based on the interaction between victim and aggressor, fitting into a pattern composed of five elements: interpersonal coherence, criminal characteristics, criminal career and forensic awareness.

- Interpersonal coherence; when the offender interacts with victims the same way he relates to people in his social environment.

- Significance of time and place; when the investigator obtains information about the area and the space where the aggressor lives. Generally, the offender chooses the place and time of the crime carefully. A certain place and a certain time appear to be very important for certain offenders, which leads to a possible representation of the places around the area of the action and the hours that are favourable to committing the premeditated criminal acts. The time and place of the action can 
Profiling as a logical form of reasoning in order to solve controversial circumstances on the crime scene provide data on the individual's perspicacity, on his work program and personal life.

David Canter also developed a theory of aggressor behaviour starting from environmental psychology. The theory includes two behavioural methods of the offender:

$>$ the first model represents the offender leaving for a short period of time from his own space of habitation in order to commit the crime;

$>$ the second model is the offender that commutes, travelling some distance from his home before engaging into the criminal activity [14].

- Criminal Characteristics; allow forensic psychologists to develop criminal classification systems and subsystems, placing them into a certain typology, so that investigators have at their disposal the most probable characteristics that define them.

- Criminal career; it refers to the criminal history of the offenders.

- Forensic awareness; refers to the offender's knowledge about the technical possibilities of investigation, so that he can try, for example, to avoid his identification from the traces left on the crime scene. Criminal history may indicate the offender's propensity of committing a particular type of crime and the information about certain behaviour of the aggressor on the scene, excluding from the range of suspects those who did not commit this type of crime in the past.

\subsection{Behavioural Evidence Analysis - BEA}

This method was born in the US and has been adopted by specialized institutions in Germany since the 80s. In 1998, departments specialized in behaviour analysis already existed in all German provinces. Here, the behavioural analyses regarding particular homicide cases are made in teams of forensic psychologists, forensic pathologists, pathologists, behavioural analysts. In order to improve communication between them, they are recommended introductory and specialization courses through which each of the specialists can familiarize with their colleagues' field. Thus, "since the introduction of behavioural analysis method in Germany, 49 tests have been carried out in unsolved homicide cases of the German Federal Police Office. In 30 cases, autopsy reports were assessed. This retrospective examination led to results that were not indicative enough for behavioural analysis.

In Germany behavioural analysis represents the complex information processing system so as to obtain several perspectives of investigation solving. In this way, behavioural analysis greatly reduced the lack of information, speeded up the decision making process and expedited the case [15].

Recently, the American profiler Brent Turvey, as a result of the problems he encountered along his career, has developed a method known the BEA method, which tries to cover the vulnerable parts of the other methods, using all the traces, 
Palcu P., Morostes A.F., (2016)

Profiling as a logical form of reasoning in order to solve controversial circumstances on the crime scene

the material evidence found at the crime scene, the aggressor's behaviour and the victim's characteristics. Many professionals fall into two extremes when it comes to the classification of the victims, they either deify [16] it, or they vilify [17] it. The deification means idealization of the victim, who can be a student, a missing person, "predefined by the press and public opinion", whereas the concept of vilification outlines the tendency to belittle the victim, and the crimes are trivialized.

Thus, Turvey states that BEA consists of considering the crime in four distinct stages: Equivocal Forensic Analysis, Victimology, Crime Scene Characteristics, Offender Characteristics [18].

$>$ Equivocal Forensic Analysis; when engaging in the analysis and assessment of all the material means of evidence and carrying out scientific research of all materials collected from the crime scene, in order to highlight the importance of multiple identification opportunities or evidence interpretation.

$>$ Victimology; when data concerning the identity of the offender can be obtained. A record of the victim is created, which contains data such as: identity, gender, nationality, ethnic origin, physical characteristics, marital status, profession, age, weight, etc. All the data recorded can form a picture on the reason, the preferences, the type of victim the aggressor targets, even the latter's distinctive marks. In research, there are four types of risks regarding the victim [19] that must be taken into consideration

- Low-risk victim; refers to the personal, professional and social life of an individual, which is not normally exposed to losses and damages" because of the individual's work environment.

- Medium-risk victim; in this case, the three "lives" of the individual acquire a degree of exposure due to his work environment.

- High-risk medium victim; the personal, social and professional life is constantly exposed to the danger of suffering different losses.

- Victim lifestyle risk; refers to the general risks present in virtue of individual personality and due to the professional and social climate. There are also some general features of such risk: emotional outbursts, hyperactivity, anxiety, impulsivity, anger, aggression, very low self-esteem, need for attention or sympathy, carelessness, indifference, etc.[20]

$>$ Crime Scene Characteristics, when elements individualizing the crime scene are determined, they are compared with the places where other similar crimes were committed, in order to establish a possible link between them and which sometimes can lead to the same offender. For example, the location of the crime scene will be determined, whether it is in a closed or open space, in urban or rural areas, as well as the peculiarities of that space. 
$>$ Offender Characteristics is the final stage of this method, which actually develops the offender's profile and the analysis resulted from the other three stages are used in a rough, unfinished sketch of the offender's character [21].

In the foreign and Romanian specialized literature, there is a typology of mass murders as follows [22]:

\section{The Disciple}

- Follows closely the instructions of a "charismatic leader".

- The choice of such people is at the reach of the leaders.

- The motivation of the "disciple murderer" comes from outside, from the leader.

- Such a person wants to gain his leader's trust.

- Space mobility plays a very important role. Generally, the acts of cruelty committed by "the disciple murderer" are not performed in a very remote place, but very near to where the leader operates.

- The victims are individuals chosen by the leader.

\section{The family annihilator}

- This type of murderer is characterized by the fact that he kills his whole family "acting once" taking into account even their pet

- The one who commits such an act either suffered from various depressions, or has a "long history regarding alcohol consumption or abuse".

- Suffers from loneliness.

- Is familiar with the location and does not find it difficult to knock their victims down.

\section{Pseudo - commando}

- Such a person gives great importance and attention to the weapons he uses (pistols, shotguns, etc.).

- The murder, in this case, comes after a long preparation and deliberation.

- Treats people in the humblest way possible.

- Generalizes problems of injustice typical to "his world" acting under the idea of "giving the world a lesson".

- Does not take account of the victim's particularities, spatial mobility is not too important either.

\section{Dissatisfied employees}

- They are former employees who were dismissed due to health or "psychical disabilities".

- Consistently claim that they have been treated unfairly, underestimated several times.

- Paranoia or medication or any daily activity issues are the main characteristics of such behaviour.

- The choice of victims is random, from the working group or the environment where the disabled person operates.

- The area where they operate is very small. 
Profiling as a logical form of reasoning in order to solve controversial circumstances on the crime scene

\section{Set-and-run killers}

- Such criminals are "detached" from the crime scene. They place the bomb (in most cases) in the chosen location and then, from a distance, by means of sophisticated devices, trigger the bomb. However, it is not a rule that they should observe "the consequences of such act."

- They are very hard to catch, given the fact that they leave the crime scene long before the bomb is detonated.

\section{Logical forms of reasoning in offender profiling}

The analysis of the offender's behaviour and personality involves a logical approach, different depending on the type of arguments taken into account in the evaluation. Thus, the arguments, as the study elements of Logics, can be divided into two distinct types, depending on the way their premises bear the conclusions: inductive and deductive ones.

In the specialized literature, the logical forms of reasoning in the development of the offender's profile have been divided into inductive and deductive [23].

a. The inductive profile has the following characteristics:

- the premises do not give definitive solutions for the conclusions, but they only make available a basis for them and allow generalization, which, even if is not correct, is based on statistical analysis.

- starting from the other previously studied offenders' behaviour and characteristics, the suspect of the investigated case is subject to generalization, assuming that offenders in similar situations have similar motivations.

- in order to elaborate the intended statistics and develop the inductive profile, data are obtained from three sources: studies on people in detention; practical experience of the investigators, public sources, including the media.

- although it presents the advantage of speed and ease, without the need of specialists, the inductive profile has been criticized because it appeals to a population limited as number of known criminals, extending the data obtained from these to innocent people.

b. The deductive profile has the following characteristics:

- provides undeniable bases for conclusions, having as the primary objective that of clarifying the relationship between premises and conclusions.

- is the exclusive result of the proper determination of the traces discovered during the research of the crime scene, of the forensic expertise, followed by an analysis of the particular characteristics of the crime scene and the victim, so it deduces the profile of an individual who could have committed the crime with that specific victim, in the specific terms of that specific crime scene.

From this perspective, the offender's characteristics and behaviour can be deduced from several categories of information, classified as follows: [24] 
Profiling as a logical form of reasoning in order to solve controversial circumstances on the crime scene

- material means of evidence. The forensic psychologist analyses all the evidence collected on the crime scene, to ensure that they properly support the peculiarities of the criminal proceedings;

- crime scene characteristics are determined after a full assessment of the material means of evidence and they are individually determined and analysed the way they happened, in chronological order. This analysis can lead to conclusions about the motive and purpose of the offender and the way it operates;

- Characteristics of the victim. In order to study the victim's characteristics, the creation of the latter's profile is part of the creation of the aggressor's profile, as well as the use of specialized staff with experience in crime scene investigation, interpretation of laboratory analysis and knowledge in psychology. The forensic psychologist should establish a unique behaviour for the offender, by switching from a universal set of characteristics of a suspect, to the characteristics of a particular individual.

There is no explicit rule for using a particular method in a particular type of case and the methods of profiling may be adapted by the investigators depending on the needs and specifics of the investigated case.

Profiling has an extrajudicial character and not even in the United States does it represent a means of evidence that serves to reveal the truth, but as through them the crimes with unknown offender could be resolved more quickly, the identification and catching the criminal(s) also allow a comparative assessment, it is natural that this kind of investigation is in constant ascension toward earning a well-established, effective and undeniable place.

\section{Notes}

[1] Tudorel Butoi, „Investigarea criminalistica a locului faptei”, Luceafarul Publishing House, Bucharest, 2004, p. 150-154

[2] Wisconsin vs. Peter Kapaza, is the first known case, in a trial, when a profiler was allowed to offer his expertise. Peter Kupaza was charged with the murder and dismemberment of his cousin, Mwivano Mwambaski Kupaza aged 25, in July 1999. See State of Wisconsin vs. Peter Kupaza, Case No.00-CF-26 case reported by Emilian Stancu in op. cit., p. 23.

[3] Ibidem

[4] In this respect, see the following works: MacKay, R., Geographic profiling: A new tool for law enforcement, The Police Chief, December 1999, 51-59; LeBeau, J.L., Four case studies illustrating the spatial-temporal analytical of serial rapists, in Police Studies nr. 15, 1992, p. 124-145; Helms, D., The use of dynamic spatial-temporal analytical techniques to resolve emergent crime series. Work presented at the conference Crime Mapping organized by Research Center, Orland, FL., dec. 1999; Gabor, T., \& Gottheil, E., Offender characteristics and spatial mobility: An empirical study and some policy implications, in Canadian Journal of Criminology, nr. 26, 1984, p. 267-281; Brantingham, P.L. \& 
Palcu P., Morostes A.F., (2016)

Profiling as a logical form of reasoning in order to solve controversial circumstances on the crime scene

Brantingham, P.J., Criminality of place: Crime Environments and Situational Prevention 3(3), 1995, p. 5-26.

[5] Vemon J. Geberth, Sex-Related Homicide Investigation

[6] Holmes, Profiling Violent Crimes: An Investigative Tool, Sage Publication, Thousand Oaks, 1996, p. 5

[7] Ressler. R. Criminal Profiling from Crime Scene Analysis, in Behavioural Sciences of the law, nr. 4, 1986, p. 401-405

[8] Pinizzotto, A.J. Finkel, N.J., Criminal personality profiling: An outcome and process study, in Law and Human Behaviour, nr. 14, 1990, p. 215-234.

[9] Tudorel Butoi, op. cit., p. 151

[10] Emilian Stancu, op. cit., p. 35

[11] Brent Turvey, Criminal Profiling: An introduction to Behaviour Evidence Analysis, in Academic Press, San Diego, 1999; Turvey B., The Role of Criminal Profiling in the Development of Trial Strategy, in Knowledge Solutions Library, Electronic Publication, Nov., 1997

[12] See Wayne Petherick, Criminal Profiling, in Courtroom Television Network LLC, 2003; Douglas, Ressler, Burgess and Hartman: Criminal profiling from crime scene analysis, in Behavioural Sciences and the Law, 4 (1986), p. 401-426 - quoted by Emilian Stancu op. cit., p. 35.

[13] Research conducted for the development of this method was started in 1985 in England by David Canter. He was asked by Scotland Yard to try to integrate psychological concepts in the investigation technique.

[14] Emilian Stancu, op. cit., p. 37

[15] Schroer et al 2003. The significance of medico-legal findings for behavioural analysis in unsolved homicide cases. Legal Medice, p. 244 - quoted in Octavian Rujoiu in Forensic and Criminology Magazine nr. 2/2004, p. 140.

[16] The example presented by Brent Turvey $(2003,139)$ is that "of two little girls kidnapped from a bus stop. They were found dead the next day, in a place close to the place of kidnapping (less than 100 yards). The press portrayed the two victims as "two guardian angels" and the investigations did neither lead to the histories of the victims' families, nor to their houses, but rather sought for a serial killer. A year later a victimological research was conducted, observing that one of the girls had set fire, had fought with other children ... The more the investigation widened, interviews with family members, medical and psychiatric tests, there was concluded that she had been molested by a relative some time before. The investigation took another twist.

[17] "A prostitute is raped in a part of town. Three days later, another is raped six panels further from the first one. Two weeks later, another prostitute is raped in the same area. All the rapes are reported, but no evidence, no proof is taken and none of the victims had anything to do with the other. The cases are not investigated more than in the form of rape or homicide". Turvey, 2003140.

[18] Turvey Brent 2002-2003. Criminal Motivation. in Brent Turvey E.. Criminal profiling. An introduction to behavioural evidence analysis, p. 280-304 - quoted by Octavian Rujoiu, op. cit. p. 142.

[19] Turvey, 2003, p. 143.

[20] Ibidem 
Palcu P., Morostes A.F., (2016)

Profiling as a logical form of reasoning in order to solve controversial circumstances on the crime scene

[21] Emilian Stancu, op. cit., p. 38.

[22] Dietz P., 1986. Mass serial and sensational homicides. Bulletin of The New York Academy of Medicine, 62, 5, 477-491; Holmes si Holmes, 1992. Understanding massmurder: a starting point. Federal Probation, 56, 1, p. 53-62; Fox and Levin, 2003. Mass Murder: An analysis of extreme violence. Journal of applied psychoanalytic studies, 5, 1, p. 47-64 - quoted by Octavian Rujoiu in The Magazine of Forensics and Criminology nr. 2/2004, op. cit. p. 135.

[23] Emilian Stancu, op. cit., p. 38.

[24] Ibidem

\section{BIBLIOGRAPHY}

1. Bradway W.C., 1990, Crime scene behavioural analysis, Law order

2. Copson G., 1995, Coals to Newcastle: police use of offender profiling, Police research group, special interest series

3. Dietz P., 1986. Mass serial and sensational homicides. Bulletin of The New York Academy of Medicine

4. Fox and Levin, 2003. Mass Murder: An analysis of extreme violence. Journal of applied psychoanalytic studies

5. Holmes R.M. si Holmes S.T., 1992. Understanding mass-murder: a starting point.

6. Palcu P. Tactica efectuarii cercetarii la fata locului, Ed. University Press, Arad, 2012

7. Federal Probation

8. Pinizzotto, A.J. Finkel, N.J., Criminal personality profiling: An outcome and process study, in Law and Human Behaviour

9. Ressler. R. Criminal Profiling from Crime Scene Analysis, in Behavioural Sciences of the law, nr. 4, 1986

10.Stancu E., Investigarea Stiintifica a infractiunilor, Curs de Criminalistica, University of Bucharest, 1986

11.Tudorel B., „Investigarea criminalistica a locului faptei”, Luceafarul Publishing House, Bucharest, 2004

12. Turvey B. 2002-2003. Criminal Motivation. Criminal profiling. An introduction to behavioural evidence analysis 